\title{
O PAPEL DA CONFIABILIDADE NA REDUÇÃO DOS CUSTOS DE TRANSAÇÃO: REFLEXÕES ENTRE BRASIL, ESTADOS UNIDOS, JAPÃO E CORÉIA DO SUL.
}

\author{
FERRATO, Elio (kandra@uol.com.br) \\ SPERS, Eduardo Eugênio (eespers@unimep.br) \\ GIULIANI, Antonio Carlos (cgiuliani@unimep.br)
}

Mestrado Profissional em Administração pela Universidade Metodista de Piracicaba - UNIMEP

\section{RESUMO}

Dyer e Chu (2003) desenvolveram um estudo empírico a respeito da relação confiabilidade entre montadoras e fornecedores automobilísticos nos Estados Unidos, Japão e Coréia do Sul nos anos de 1993 e 1994. Baseado nos parâmetros apontados por Dyer e Chu este estudo tem o propósito de analisar a confiabilidade na relação fornecedor-comprador na indústria automobilística brasileira no ano de 2004, estabelecendo certa comparação com aqueles outros países.

A confiabilidade nas trocas econômicas tem sido vista por alguns analistas como ativo econômico de valor em razão dos custos de transação (ex ante e ex post) inferiores, os quais permitem maior flexibilidade para responder às condições de mercado em constantes mudanças e induzem a um maior compartilhamento de informações, que provoca melhorias na coordenação e estrutura de governança, juntando assim esforços para minimizar as ineficiências, fatos que sustentam duas das hipóteses do estudo. Uma quarta hipótese que trata de verificar se quanto maior a confiabilidade entre as partes menores são os custos de transação e melhor performance dos lucros não têm a evidência necessária neste estudo.

Baseado nos dados do trabalho de Dyer e Chu, o objeto deste estudo é realizar uma análise qualitativa da relação entre uma montadora estrangeira instalada no Brasil e alguns de seus fornecedores de autopeças.

Nas considerações finais deste trabalho ficam reforçados os argumentos teóricos de que a confiabilidade reduz custos de transação nas relações de troca e incrementa o compartilhamento de informações na relação fornecedorcomprador.

Palavras-chave: Confiabilidade; relação fornecedor-comprador; indústria automobilística; custos de transação.

\section{ABSTRACT}

Dyer \& Chu (2003) have developed an empirical study regarding the trustworthiness in the relationship between assemblers and suppliers in the automotive industry in the United States, Japan, and South Korea during the years 1993 and 1994. Based on parameters pointed out by Dyer and Chu this study aims to analyse the trustworthiness in the relationship supplier-purchaser in the brazilian automotive industry in the year 2004, establishing a certain 
Revista Eletrônica de Ciência Administrativa (RECADM) - ISSN 1677-7387

Faculdade Cenecista de Campo Largo - Coordenação do Curso de Administração v. 3, n. 2, nov./2004 - http://revistas.facecla.com.br/index.php/recadm/

comparison with those other countries. Trustworthiness in the economical exchanges have been seen by some analysts as a valuable economic asset due to lower transaction costs (ex ante and ex post), which allow greater flexibility to respond to the market conditions in permanent changes and induce to a superior information sharing, that provoke improvements in the governance structure coordination, adding up, this way, efforts to minimize the inefficiencies, facts that support two of the four hypothesis of this study. A fourth hypothesis which aims to check whether the bigger the trustworthiness between the parties the least the transaction costs and better profit performance does not have the necessary evidence in this study. Based on Dyer and Chu's work data, the object of this study is to perform a qualitative analysis of the relationship between a foreign auto assembler installed in Brazil and some of its parts suppliers. In the final considerations of this work the theoretical arguments that the trustworthiness reduces the transaction costs in the exchange relationship and improves the information sharing in the relationship supplier-purchaser are reinforced.

Key-words: trustworthiness; supplier-purchaser relationship; automotive industry; transaction costs reduction

\section{I - INTRODUÇÃO}

Este capítulo tem como objetivo apresentar o problema de pesquisa, os objetivos, as hipóteses levantadas e a sua justificativa, a estrutura deste trabalho, expondo, desta maneira, as primeiras considerações sobre a relação entre uma montadora e seus fornecedores.

\subsection{O problema de pesquisa}

As mudanças institucionais ocorridas em nível mundial, a partir da década de 1980, suscitaram, na indústria automobilística, modificações estruturais que implicaram diretamente nas relações inter-organizacionais, mais especificamente, entre montadoras e seus fornecedores.

Destacam-se como mudanças no ambiente institucional a queda do muro de Berlin, a abertura do mercado chinês ao mundo, a arrancada tecnológica da Coréia do Sul, o resfriamento da economia japonesa, o fim da guerra fria encabeçada pelos Estados Unidos, entre outras. No Brasil, por sua vez, entre as mudanças no ambiente institucional, em especial após o início da década de 1990, estão: a abertura das importações, a promoção do desenvolvimento tecnológico, a entrada de novas montadoras no mercado, a instituição do Plano Real, o fomento às exportações, entre outras.

Se por uma lado aquelas mudanças favoreceram o impulso industrial de modo geral nos países, por outro, a relação entre montadoras e seus fornecedores 
Revista Eletrônica de Ciência Administrativa (RECADM) - ISSN 1677-7387

Faculdade Cenecista de Campo Largo - Coordenação do Curso de Administração v. 3, n. 2, nov./2004 - http://revistas.facecla.com.br/index.php/recadm/

sofreu transformações e tornou-se complexa. Estudar esta relação sob a ótica da confiabilidade, sua possível implicação na redução dos custos de transação e o compartilhamento da informação é o objetivo principal deste trabalho.

Dyer e Chu (2003) investigaram empiricamente essa relação objeto do estudo junto a 344 empresas tanto fornecedoras de peças automobilísticas quanto montadoras de veículos nos Estados Unidos, Japão e Coréia do Sul. No Brasil o estudo qualitativo se restringe a uma montadora de automóveis e dez de seus fornecedores de peças de suprimento a título de ensaio para uma correlação com os estudos de Dyer e Chu.

\subsection{Objetivos do trabalho}

Como objetivo geral, propõe-se comparar os resultados dos estudos realizados por Dyer e Chu nos Estados Unidos, Japão e Coréia do Sul, nos anos de 1993 e 1994, relativamente à verificação do papel da confiabilidade na redução dos custos de transação, com os resultados das análises levantadas no Brasil no ano de 2004 , usando os mesmos critérios de investigação. Como objetivos específicos, pretende-se caracterizar o que é confiabilidade, descrever como ela é percebida ex ante e ex post pelos agentes econômicos envolvidos, qual a relação da confiabilidade com a redução dos custos de transação e sua influência no compartilhamento da informação.

Por ex ante entende-se aqui as características da relação antes de ela efetivarse concretamente entre os agentes econômicos e ex post é entendida como a situação em qualquer momento após a efetiva concretização de um contrato de fornecimento que pode caracterizar a existência da relação.

\subsection{Hipóteses da pesquisa}

Neste item, são descritas quatro hipóteses principais formuladas por Dyer e Chu para este trabalho. Vale ressaltar que no Brasil são levantadas as mesmas hipóteses no estudo qualitativo:

H1: Quanto maior for a confiança do fornecedor sobre a montadora, menores os custos de transação ex ante incorridos entre aqueles agentes econômicos.

Acredita-se que a confiabilidade tem uma relação inversa aos custos de monitoramento e de imposição do contrato por duas razões principais. 
Revista Eletrônica de Ciência Administrativa (RECADM) - ISSN 1677-7387

Faculdade Cenecista de Campo Largo - Coordenação do Curso de Administração v. 3, n. 2, nov./2004 - http://revistas.facecla.com.br/index.php/recadm/

Primeiramente, sob condições de alta confiabilidade, os agentes econômicos despendem menos tempo e recursos no monitoramento para verificar se a outra parte está atenta ou esquivando-se daquilo que foi acordado. Se cada agente econômico acredita que o outro não vai ter atitudes oportunistas, então, ambas as partes podem concentrar menos esforços sobre o monitoramento. $\mathrm{Na}$ contrapartida, agentes econômicos sem a confiabilidade de "boa-vontade", os quais vão contar apenas com a confiabilidade por força de contrato, vão ter de fazer investimentos tanto para monitorar as ações da outra parte, quanto para fazer valer os termos do contrato.

Em segundo lugar, a confiabilidade pode reduzir custos de transação através da diminuição do tempo e recursos que os agentes gastam na negociação e busca de solução de problemas ex post, ou seja, aqueles surgidos ao longo da vigência do contrato. Se a confiabilidade é alta, cada agente acredita que a outra parte está agindo em "boa-fé" e, portanto, vai ter uma percepção sobre pressupostos comportamentais de modo positivo. Consequentemente, os agentes econômicos com alta confiabilidade vão gastar menos tempo tentando solucionar questões surgidas durante o curso da transação devido o fato de que a confiança mútua vai buscar remediar quaisquer desavenças de maneira justa e limpa.

H2: Quanto maior a confiabilidade do fornecedor sobre a montadora, menores os custos de transação ex post incorridos pelos agentes envolvidos. Nesta hipótese em particular, os custos ex post se referem a custos tanto de monitoramento quanto para fazer valer os termos do contrato.

Quando consideradas as hipóteses 1 e 2 juntas (maior a confiabilidade, menores os custos de transação ex ante e ex post), naturalmente deve-se concluir que, quanto mais o fornecedor confiar na montadora, menor o total dos custos de transação incorridos pelos agentes. Não se considera aqui uma hipótese formal separada porque ela provém diretamente das duas primeiras hipóteses.

Confiabilidade e compartilhamento de informação. Dyer e Chu são da teoria que há um relacionamento positivo entre confiabilidade da montadora e compartilhamento de informação com o fornecedor por duas razões primárias. Primeiramente, se o fornecedor pode confiar que a montadora não vai assumir comportamento oportunista, ele vai estar disposto a compartilhar informações confidenciais como custo de produção ou custo de desenho de produtos ou inovações de processo, entretanto, um fornecedor vai voluntariamente compartilhar estas informações somente se ele acredita que a montadora não vai roubas suas idéias ou/e passá-las a concorrentes ou não vai tentar "espremer" as margens de lucro do fornecedor. $\mathrm{Na}$ ausência da confiabilidade, o compartilhamento de informação sobre custos ou novas idéias/tecnologias é improvável porque esta poderia ser usada indevidamente ou oportunistamente. 
Em segundo lugar, a falta de confiabilidade pode causar no fornecedor a retenção de informações potencialmente relevantes que poderiam ser úteis na solução de problemas. Por exemplo: os fornecedores podem não querer compartilhar informações sobre produção ou problemas de desenho se eles não acreditam na montadora para trabalhar cooperativamente na solução de problemas conjunto. De modo particular, fornecedores podem ficar relutantes em compartilhar qualquer informação que exponha suas fraquezas das suas operações ou de suas estruturas de custos, mesmo que o compartilhamento de tais informações possam resultar em sugestões valorosas da montadora que poderiam levar a soluções efetivas.

H3: Quanto maior a confiabilidade do fornecedor sobre a montadora, mais o fornecedor vai compartilhar informações (confidenciais) valiosas com a montadora.

Confiabilidade, Custos de Transação e Performance. Se a confiabilidade implica efetivamente em custos menores de transação (e aumenta o compartilhamento de informação) na forma anteriormente descrita, então quanto maior for a confiabilidade por parte da montadora, menores os seus custos totais, portanto, maior a sua lucratividade, pois, conforme Williamson (1991), as empresas que efetivamente economizam nos custos de transação, vão apresentar performance superior. Realmente, argumenta-se que a estratégia é economizar nos custos de transação. Desta forma, mantendo todas as demais variáveis iguais, uma montadora com a reputação de "confiável" nos relacionamentos de troca deveria ter menor custos de transação, os quais poderiam ser traduzidos como melhor desempenho nos lucros.

H4: Mantidas todas as demais variáveis iguais, quanto maior a confiabilidade da montadora sobre os fornecedores, menores os seus custos de transação e melhor a performance de seus lucros

Variáveis Controláveis: Investimentos na Relação Especificidade de Ativos e Tamanho do Fornecedor. Dyer e Chu (op. cit) empregam um investimento do fornecedor em ativos de relação específica como uma variável para controlar: (1) a vulnerabilidade do fornecedor com relação a investimentos específicos de transação (que portanto necessita de confiabilidade) e (2) a montadora. De acordo com a Economia de Custos de Transação - ECT, trocas diferem em suas necessidades de confiabilidade (salvaguardas) e compartilhamento de informação. Em situações onde investimentos em especificidade de ativos são baixos, a confiabilidade pode ser desnecessária. Confiabilidade é necessária quando os agentes econômicos fazem investimentos em especificidade de ativos que geram a quase-renda (Klein et al. 1978). Quanto maior a especificidade de ativos maior a probabilidade de aumentar o compartilhamento de informação em razão do fato de que as trocas idiossincráticas tendem a exigir maior coordenação que as 
Revista Eletrônica de Ciência Administrativa (RECADM) - ISSN 1677-7387

Faculdade Cenecista de Campo Largo - Coordenação do Curso de Administração v. 3, n. 2, nov./2004 - http://revistas.facecla.com.br/index.php/recadm/

trocas padronizadas. Portanto, assume-se o controle em função da especificidade dos ativos devido o fato de que qualquer verificação dos efeitos da confiabilidade sobre os custos de transação e o compartilhamento da informação deve levar em conta os atributos da troca (notadamente da especificidade de ativos) que podem influir estes constructos.

Dyer e Chu (op. cit) empregam também o controle para o tamanho do fornecedor (volume de vendas à montadora) porque a relação entre montadoras e seus fornecedores pequenos ou grandes podem diferenciar-se, sobretudo se pensamos em exemplificar somente fornecedores do nível I ou "tier one" . Nível I ou tier one referem-se à estrutura na cadeia de fornecimento de peças à montadora. Nível I ou tier one podem ser tanto aquelas empresas que fornecem sistemas, subconjuntos ou módulos à montadora, quanto um fornecedor de componente importante ou estratégico para a montadora. No ponto 2.2. deste trabalho mostra-se a estrutura da cadeia de fornecedores no Brasil.

Reconhece-se que a direção de causalidade entre confiabilidade e compartilhamento de informação é aberta a debates. Por exemplo, pode-se questionar se o compartilhamento de informação leva a uma maior confiabilidade ou vice-versa. Espera-se algum grau de causalidade recíproca com essas variáveis onde a confiabilidade tanto influencia como é influenciada pelo compartilhamento de informação. Entende-se por compartilhamento de informação como uma extensão do qual o fornecedor divide informações de propriedade/confidenciais com a montadora, ou seja, ele passa informações que não compartilharia se não houvesse algum grau de confiabilidade. Obviamente, após o compartilhamento da informação, a confiabilidade aumentaria ainda mais.

\subsection{Justificativa do trabalho}

Muitos investimentos são feitos entre fornecedores e montadoras na indústria automobilística para a concretização de uma relação de negócios, que pode levar entre 12 e 24 meses, o que representa uma boa soma de dinheiro quando contabilizado o envolvimento de pessoal, equipamentos, horas de estudos, medições, viagens, mobilização de veículos, etc. Este estudo de Dyer e Chu sugere, de alguma forma, como vale estudar e desenvolver mecanismos para encurtar esse período de conhecimento mútuo entre os agentes econômicos envolvidos nas transações ex ante e propiciar meios para a manutenção da confiabilidade no período ex post.

\subsection{Estrutura do trabalho}


Revista Eletrônica de Ciência Administrativa (RECADM) - ISSN 1677-7387

Faculdade Cenecista de Campo Largo - Coordenação do Curso de Administração v. 3, n. 2, nov./2004 - http://revistas.facecla.com.br/index.php/recadm/

Este trabalho está estruturado basicamente na introdução, composta do problema de pesquisa, objetivos, hipóteses e justificativa; em uma breve descrição do setor automobilístico brasileiro, pequena revisão bibliográfica acerca da Confiabilidade, a metodologia, análise dos dados e considerações finais.

\section{O Setor Automotivo no Brasil}

Peter Drucker (1946) denominou a indústria automobilística de "a indústria das indústrias" . De acordo com Woomack et al (1993), a indústria automobilística continua sendo a expressão mais forte no segmento industrial em nível mundial, com produção superior a 50 milhões de veículos. Foram produzidos, em 2001, 56 milhões de veículos novos, de acordo com o anuário estatístico publicado pela Associação Nacional dos Fabricantes de Veículos Automotores (ANFAVEA, 2003).

Tomando os respectivos volumes de produção de veículos pelos países que compõem o objeto deste trabalho no ano de 2001, temos:

Estados Unidos produziram 11,4 milhões de unidades, Japão produziu 9,8 milhões, Coréia do Sul produziu 2,9 milhões e Brasil produziu 1,8 milhões de unidades.

Em 2003, a indústria automobilística brasileira, composta pelas montadoras mais as indústrias de autopeças, respondeu por $11 \%$ do PIB industrial e $4,5 \%$ do PIB brasileiro. As relações inter-setoriais automotivas indicam a presença de 200 mil empresas. A atividade gera 1,3 milhão de empregos diretos e indiretos e paga $\mathrm{R} \$ 10$ bilhões/ano em tributos, de acordo com o boletim de fevereiro de 2004 da ANFAVEA.

\subsection{Mudanças no setor automobilístico no Brasil}

Alguns autores atestam que, a cadeia automotiva brasileira, em consonância com sua equivalente cadeia global, mantém uma relação hierarquizada na coordenação da produção. Esse modo de relação que a montadoras estabelecem com seus fornecedores, de alguma forma transfere a eles os ônus das estratégias da competitividade. Agregam ainda algum autores que as montadoras, na tentativa de reduzirem seus custos, tendem a concentrar seus esforços estratégicos em áreas que apresentem maior liquidez na produção automotiva, ou seja, na pesquisa e desenvolvimento, no lançamento de novos produtos, na fortificação ou promoção da marca e na venda de seu produto acabado.

A partir da década de 1990, com a globalização e abertura do mercado, as mudanças estruturais na indústria brasileira implicou em relação complexa entre clientes e fornecedores. O sentido de relação complexa aqui entende-se pelo fato de que as montadoras se obrigaram a cortar custos inclusive o número de fornecedores de peças de suprimento e estes, por sua vez, tiveram 
Revista Eletrônica de Ciência Administrativa (RECADM) - ISSN 1677-7387

Faculdade Cenecista de Campo Largo - Coordenação do Curso de Administração v. 3, n. 2, nov./2004 - http://revistas.facecla.com.br/index.php/recadm/

de se adaptar às novas exigências. Quadros et al (2000) aborda três mudanças significativas ligadas ao processo de concentração e desnacionalização que modificaram a organização da cadeia.

Como primeira mudança, tem havido um intenso processo de concentração e desnacionalização, principalmente, entre as empresas produtoras de autopeças para suprimento no Brasil. Com a elevação das exigências das montadoras, no sentido de produção em escala global e comercialização global de seus principais fornecedores, houve um crescimento do movimento de aquisições e fusões, tendo como efeito uma desnacionalização ampla. A maioria dos grandes produtores de autopeças nacionais como Cofap, Metal Leve, Maxion, Varga e Nakata, entre outros, teve o controle de capital transferido para grupos de origem estrangeira.

Como segunda mudança, há significativas modificações na divisão do trabalho, especialmente entre as montadoras e os fornecedores de autopeças de suprimento de maior porte, entre elas se destacam o co-design (desenvolvimento de produto compartilhado) e a produção modular (montagem compartilhada).

Tendo em vista a concentração de esforços das montadoras mais sobre o marketing que propriamente na produção, alguns dos principais fornecedores do primeiro nível, como Delphi, Visteon, Magneti Marelli, Valeo, Siemens, entre ouros, passaram também a fornecer módulos funcionais montados, no lugar de componentes individuais (montagem modular). Em consequência disso, a importação de componentes veiculares aumentou consideravelmente. Conforme Quadros(2002), ao final da década de 1990, o valor das importações de autopeças no Brasil havia se estabilizado em torno de $25 \%$ a $30 \%$ do valor do consumo aparente (contra menos de $10 \%$ no início da década).

Como terceira mudança, a maior internacionalização das transações de produtos e peças, e a consequente redução da defasagem tecnológica dos produtos e processos, têm aumentado as exigências de qualidade e produtividade que as montadoras exigem dos seus fornecedores. Em linha com a estratégia global das montadoras, a política definida pelo governo federal no Regime Automotivo possibilitou uma modernização significativa das plantas produtivas e a vinda de novas montadoras entrantes ao país, representando um aumento significativo de produtividade.

Esse conjunto de mudanças no setor automotivo implica em relações desequilibradas e assimétricas entre montadoras e fornecedores, criando assim uma hierarquia de fornecedores dentro da cadeia de valor.

Esse panorama se aplica cabalmente às montadoras que já se encontravam instaladas no país anteriormente à década de 1990, entretanto, para as novas entrantes no setor, especialmente a partir de 1992, estas tiveram a oportunidade de se instalarem no país com simples montagem de seus agregados inicialmente e, depois de sondarem devidamente o mercado, puderam ou determinar seus fornecedores locais no mercado brasileiro ou 
Revista Eletrônica de Ciência Administrativa (RECADM) - ISSN 1677-7387

Faculdade Cenecista de Campo Largo - Coordenação do Curso de Administração v. 3, n. 2, nov./2004 - http://revistas.facecla.com.br/index.php/recadm/

convidar seus fornecedores de autopeças de suprimento dos seus países de origem para se instalarem no Brasil.

Assim, aquela hierarquia antes existente, válida para praticamente todos os fornecedores, dá lugar a uma situação de independência, especialmente no caso dos fornecedores de componentes, categorizados no primeiro nível da estrutura de relação de fornecimento da cadeia automotiva. Por agregado entende-se aqui como conjuntos principais do veículo: motor, cabina, eixos dianteiro e traseiro, caixas-de-câmbio, direção, etc.

\subsection{Relações entre montadoras e seus fornecedores no Brasil}

Através da política de "Industrialização por Substituição das Importações" na década de 1970, como forma de proteção ao mercado nacional, houve um incremento do índice de nacionalização das peças de autoveículos, em torno de $95 \%$, fomentando assim o crescimento do número de fornecedores de autopeças nacionais. A partir da metade da década de 1980, o governo promoveu a expansão das exportações através da concessão de benefícios fiscais à exportação, o que provocou uma intensificação nas relações entre montadoras automotivas e seus fornecedores de peças, redundando em incremento tecnológico e dos serviços para ambas as partes.

Com a globalização efetiva e a abertura comercial, a partir da década de 1990, registrou-se uma nova era de acirramento da competição internacional e de novos desenhos na cadeia produtiva. Até mesmo os melhores preparados para atender o mercado externo tiveram que dobrar-se às estratégias globais das montadoras, resultando na aquisição de boa parte dessas empresas por fabricantes estrangeiros.

Em função dessa concorrência apertada a nível global, as montadoras tiveram de reduzir seus custos para manterem-se no mercado, quando não obrigadas à ação extremada da fusão, reduzindo o número de fornecedores de autopeças de suprimento. Estes últimos, por sua vez, tiveram de reestruturar-se para sobreviver no mercado competitivo comercial e tecnologicamente. Daí surge uma nova relação entre fornecedores e montadoras e ai está o interesse principal deste trabalho.

A cadeia de valor da indústria automotiva brasileira é composta pelo grupo de montadoras, de um lado, e o grupo de fornecedores de autopeças, de outro, levando-se em conta o fluxo de transações comerciais formais. As relações de fornecimento na cadeia automotiva brasileira se arquitetam em três níveis em relação à montadora. O $1^{\circ}$ nível (tier one) é caracterizado pelo fornecimento direto às montadoras.

Este primeiro nível é formado principalmente por grandes empresas globais, a maioria delas controladas por capital estrangeiro, tais como: MWM, Eaton, R. Bosch, Delphi, Visteon, Cummins, entre outras. Uma parte considerável dessas empresas fornece sistemas completos, módulos ou subsistemas 
Revista Eletrônica de Ciência Administrativa (RECADM) - ISSN 1677-7387

Faculdade Cenecista de Campo Largo - Coordenação do Curso de Administração v. 3, n. 2, nov./2004 - http://revistas.facecla.com.br/index.php/recadm/

(motores, caixas-de-câmbio, eixos dianteiro e traseiro, sistema de freios, etc). Também estão nesse nível de fornecimento (10 tier), produtores de componentes com graus diferentes de complexidade, incluindo empresas de capital nacional de menor porte.

No $2^{\circ}$ nível (tier two)), encontram-se os fornecedores de componentes e alguns de sistemas, módulos ou subconjuntos para empresas do primeiro nível. Este nível é constituido por número representativo de pequenas e médias empresas de capital nacional. As firmas de $3^{\circ}$ nível são fornecedoras de commodities simples para as empresas do primeiro e da segundo níveis. A Figura 1.1 ilustra, de modo simplificado, as relações de fornecimento na cadeia automotiva, ou seja, montadora e fornecedores.

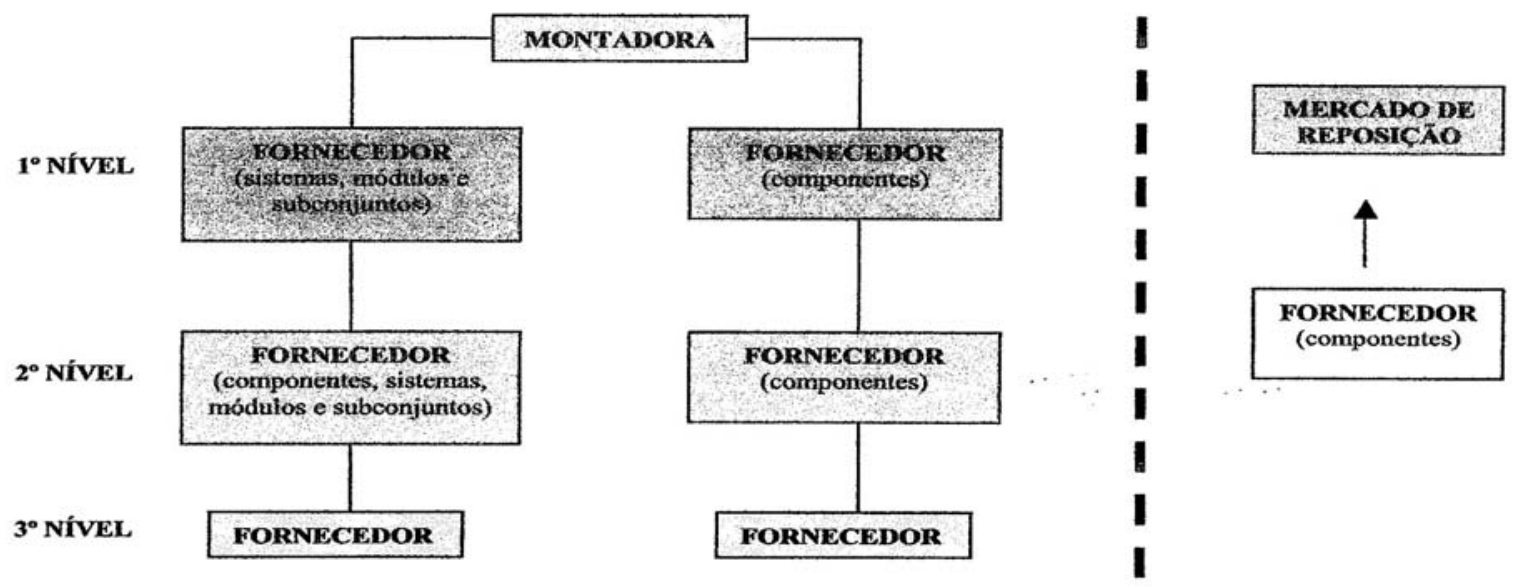

Figura 1.1. - Estrutura de relação de fornecimento da Cadeia Automotiva no Brasil

Fonte: Adaptado de Salerno et al. 2002, conforme Quintão (2003)

\section{III - Confiabilidade - Definição}

De acordo com Dyer e Chu (op. cit), estima-se que a confiança surja a partir de situações onde haja uma permuta de confiabilidade na relação entre as partes em uma transação onde: (1) são feitos esforços para que as partes se comportem de acordo com os compromissos assumidos e (2) sejam feitos ajustes, em razão de mudanças estruturais de mercado, de maneira percebida como razoável ou justa pelo outro agente econômico envolvido na negociação e (3) que não se tome vantagem excessiva do parceiro na transação mesmo quando houver oportunidade para isto (MAYER et al., 1995).

Deste modo, a definição caracteriza a confiança interfirma como um constructo baseado em componentes que se relacionam: acreditar, justiça e boavontade/benevolência. Como a noção de boa-vontade é parte da definição de 
Revista Eletrônica de Ciência Administrativa (RECADM) - ISSN 1677-7387

Faculdade Cenecista de Campo Largo - Coordenação do Curso de Administração v. 3, n. 2, nov./2004 - http://revistas.facecla.com.br/index.php/recadm/

confiabilidade, como definida aqui, não é baseada em contratos mas sim em mecanismos não contratuais.

Conceitualmente, as organizações não são capazes de confiar uma na outra; confiança é um fenômeno de nível que subjaz ao interior e tem sua base focalizada nas pessoas como indivíduos. Uma pessoa pode depositar confiança em outra ou em um grupo de pessoas, por exemplo, dentro de uma organização. Entretanto, as pessoas, podem, em uma organização, compartilhar de uma orientação em relação a indivíduos de uma outra organização. A partir desta perspectiva, a confiabilidade interorganizacional descreve a extensão à qual membros organizacionais percebem coletivamente a confiabilidade em relação à outra firma. (ZAHEER et al, 1998, p.142).

Neste estudo considera-se a confiança sob a ótica da orientação coletiva entre um fornecedor de peças sobre seu cliente, a montadora.

Esta pesquisa verifica uma combinação de relacionamentos de transação na qual a confiabilidade deve ser considerada como importante. Diversos autores questionam se risco, ou ter algo investido no outro agente econômico, é requisito para a confiabilidade. A necessidade de confiabilidade surge somente em situações de risco (MAYER et al., 1995).

O risco está presente e confiabilidade é necessária nas circunstâncias onde parceiros em um negócio fazem investimentos específicos de transação e onde haja um alto grau de incerteza ambiental.

\section{Metodologia}

O estudo de Dyer e Chu (2003), investiga a relação entre a confiabilidade do fornecedor de peças sobre a montadora e custos de transação e compartilhamento de informação em uma amostragem de 344 fornecedores de peças a montadoras que trocam relacionamentos entre si nos Estados Unidos, Japão e Coréia do Sul. O estudo feito no Brasil, usa a mesma ótica de Dyer e Chu quanto às hipóteses, cuja amostragem inicial é composta de 11 empresas, todas localizadas no Estado de São Paulo, com a maioria delas em um raio de 200 km da cidade de Campinas.

O desenvolvimento deste trabalho se deu dentro de um mesmo segmento econômico e funcional, numa mesma região, para testar as mesmas hipóteses como por Dyer e Chu naqueles outros países. No caso do estudo brasileiro, não se trata de estudo empírico, senão de entrevistas semi-estruturadas qualitativas, especialmente em virtude de algumas considerações relevantes para a consecução da pesquisa de Estudos Multicasos. De acordo com Yin (1994), na eventualidade de um mesmo estudo poder conter mais de um caso simples, sugere-se usar o formato de estudo qualitativo de multicasos.

\subsection{População e amostra}


Revista Eletrônica de Ciência Administrativa (RECADM) - ISSN 1677-7387

Faculdade Cenecista de Campo Largo - Coordenação do Curso de Administração v. 3, n. 2, nov./2004 - http://revistas.facecla.com.br/index.php/recadm/

Estabeleceu-se um conjunto amplo e diversificado para testar as hipóteses pelas seguintes razões: Primeiramente, o Japão tem sido descrito como um ambiente de alta confiabilidade onde a confiança interfirmas é o fator chave que facilita as trocas e cria vantagens competitivas às empresas japonesas (DORE, 1983; SAKO, 1991; HILL, 1995). Desta forma Dyer e Chu quiseram estudar empiricamente a extensão à qual a confiabilidade interfirma é correlacionada com comportamentos de criação de valores no Japão, por exemplo: compartilhamento de informação, custos de transação reduzidos, etc.

Em contrapartida, os Estados Unidos tem sido frequentemente classificado como de ambiente de baixa confiabilidade em relação ao Japão (DORE, 1983; SAKO, 1991; SHANE, 1994). Fukuyama (1995), no entanto, recentemente afirmou que os Estados Unidos, assim como o Japão, têm ambiente de alta confiabilidade, particularmente quando comparados com outros países menos desenvolvidos. A Coréia do Sul foi adicionada ao estudo porque sua cultura é semelhante a do Japão e suas práticas gerenciais tem sido influenciadas pelas firmas americanas, especialmente na indústria automotiva onde relacionamentos de parceria tem sido estabelecidos entre Daewoo e General Motors (A GM detinha 50\% da Daewoo até 1994) e Kia e Ford.

A amostra consistiu de três montadoras americanas (General Motors, Ford e Chrysler), duas japonesas (Toyota e Nissan) e três coreanas (Hyundai, Daewoo e Kia) e uma amostragem de seus fornecedores tier one. Aquelas companhias representaram mais de dois terços do mercado automotivo de cada país. Das montadoras foram entrevistados 31 executivos da área de compras e pessoal de vendas e de engenharia de 70 fornecedores de peças (30 americanos, 20 japoneses e 20 coreanos).

No Brasil a amostragem consistiu de uma montadora de origem japonesa e onze de seus fornecedores de peças, cujas origens respectivas de países são: Japão, Alemanha e Estados Unidos. Nenhum fornecedor de peças genuinamente brasileiro foi incluido no rol das empresas pesquisadas. Os nomes da montadora e dos onze fornecedores foram suprimidos deste trabalho a pedido dos próprios respondentes e, por questões de ética, estamos atendendo àquela solicitação.

\subsection{Instrumento e método de coleta}

Para minimizar preconceitos por parte de informantes-chave e seguir a recomendação geral para usar os respondentes mais experientes, perguntamos aos gerentes de compras de cada montadora para identificar o executivo do fornecedor com maior responsabilidade no gerenciamento da relação do dia-a-dia. Alguém poderia perguntar se um simples respondente teria conhecimento suficiente e habilidades para assessar a confiabilidade de orientação coletiva dos indivíduos na sua organização com relação à montadora. Apesar de que, normalmente, sejam preferidas as respostas de múltiplos respondentes, acredita-se que os informantes da pesquisa de Dyer e Chu estavam muito bem informados devido às seguintes razões: Primeiro, os 
Revista Eletrônica de Ciência Administrativa (RECADM) - ISSN 1677-7387

Faculdade Cenecista de Campo Largo - Coordenação do Curso de Administração v. 3, n. 2, nov./2004 - http://revistas.facecla.com.br/index.php/recadm/

informantes-chave estavam empregados em suas respectivas organizações por uma média de 16 anos; então eles tinham uma longa história de trabalho com a montadora. Durante as entrevistas, o grupo de executivos do fornecedor verificava as respostas de cada um para chegar a uma resposta consensual do grupo. O grau de similaridade em suas respostas foi impressionante; raramente as respostas variavam mais de um ponto sobre sete na escala Likert. Consequentemente, Dyer e Chu crêem que as respostas dos informanteschave representam com segurança as respostas de informantes múltiplos.

As respostas utilizáveis foram obtidas junto a 135 americanos (taxa de resposta de 66\%), 101 japoneses (taxa de resposta 68\%) e 108 coreanos (taxa de resposta de 55\%) representando os fornecedores. A coleta de dados ocorreu entre os anos de 1993 e 1994, refletindo dados de 1993.

A pesquisa no Brasil se restringiu a um contato da montadora e onze de seus fornecedores; a maioria absoluta de respondentes são os contatos com a montadora desde a sua fundação no país, de modo geral o gerente de contas que trata dos assuntos com a montadora desde o primeiro contato até os dias de hoje, com contatos minimamente semanais com a fábrica. Alguns dos contatos nos fornecedores são ex-funcionários da montadora em razão da bagagem necessária para facilitar, primeiramente, a questão linguística, e, em segundo lugar, a complexa tramitação de approach com a montadora ex ante e ex post. Vale mencionar que a montadora pertence ao grupo de novos entrantes no mercado automobilístico brasileiro a partir de 1997, portanto, não são contatos tão antigos como os mencionados por Dyer e Chu, à exceção de um caso onde o gerente de produção, que às vezes faz o papel de gerente de vendas, trabalhou para a empresa matriz no Japão antes de estabelecer sua fábrica no Brasil a convite da montadora.

Muito proximamente como detetado na pesquisa de Dyer e Chu, no Brasil encontraram-se poucas respostas com variações de mais de dois pontos sobre sete na escala Likert. Para a consecução das entrevistas, delinearam-se algumas perguntas qualitativas, semi-estruturadas, para livre desenvolvimento do raciocínio pelo respondente.

\subsection{Medidas operacionais}

Confiabilidade. Para serem consistentes com estudos anteriores, Dyer e Chu (op. cit.) tiveram que medir a confiabilidade da montadora usando pontos projetados em múltipla escala para medir a extensão com a qual o fornecedor acredita que a montadora não apresentaria comportamento oportunista. Confiabilidade (entendida aqui como confiança) foi operacionalizada como a soma das seguintes sub-medidas que são reflexo de um constructo simples unidimensional:

(1) Até que ponto o fornecedor acredita que a montadora deveria tratá-lo de forma justa ou razoável;

(2) Até que ponto a montadora tem a reputação de "confiável" entre a comunidade de fornecedores em geral; 
Revista Eletrônica de Ciência Administrativa (RECADM) - ISSN 1677-7387

Faculdade Cenecista de Campo Largo - Coordenação do Curso de Administração v. 3, n. 2, nov./2004 - http://revistas.facecla.com.br/index.php/recadm/

(3) Se houvesse oportunidade, até que ponto o fornecedor perceberia que a montadora vai em algum momento tomar vantagem desleal do fornecedor.

Cada item da escala foi mensurado sobre um ponto sete da escala Likert ( $1=$ nenhum; 7 = de grande extensão). O alfa de Cronbach deste constructo foi de 0.84 , indicando alta confiabilidade. No Brasil, esse índice, em relação à montadora japonesa, o índice chega próximo do 0.90, portanto, de alta confiabilidade também.

Custos de Transação. Para medir os custos de transação, os fornecedores foram solicitados a estimar: (a) o número de "dias por pessoa" de contatos entre a sua organização e a montadora no ano anterior e (b) que porcentagem do seu tempo de comunicação face-à-face com a montadora envolveu negociações de preço ou contrato, ou discussões ex post na forma de imputar responsabilidade sobre problemas. De acordo com os fornecedores, a comunicação face-à-face representa a forma de comunicação mais importante e cara entre fornecedores e montadoras.

Não se menciona neste estudo a especificidade de ativos locacionais para mensurar as distâncias médias entre as montadoras e seus fornecedores, portanto, a avaliação neste caso fica prejudicada. No caso do Brasil, a maioria dos fornecedores em geral, não somente os onze pesquisados, estão muito próximos das instalações da planta da montadora, razão pela qual a comunicação face-à-face não fica dispendiosa como no caso estudado por Dyer e Chu.

No caso do estudo de Dyer e Chu, portanto, os custos de transação ex ante e ex post foram medidos como o número de dias por ano que é gasto entre a montadora e o fornecedor negociando um preço ou contrato (contratação ex ante) ou discutindo de quem é a responsabilidade por este ou aquele problema (discussão ex post).

Mais precisamente, essas medidas foram calculadas da seguinte forma: 
Revista Eletrônica de Ciência Administrativa (RECADM) - ISSN 1677-7387

Faculdade Cenecista de Campo Largo - Coordenação do Curso de Administração v. 3, n. 2, nov./2004 - http://revistas.facecla.com.br/index.php/recadm/

Compartilhamento de informação do fornecedor. O compartilhamento de informação foi operacionalizado como na proporção em que o fornecedor passa informações confidenciais e de propriedade a engenheiros e compradores da montadora (1 a 7 na escala Likert). De modo particular, 0 compartilhamento de informações sensíveis, tais como custos e propriedade de tecnologia, demonstrou ser um fator crítico para a implementação com sucesso do esforço-conjunto montadora e fornecedores para a minimização de custos.

Variável controle: Especificidade de Ativos. A especificidade de ativos refere-se a investimentos de capital em maquinários customizados, ferramentas, estampas, etc. A especificidade de ativos foi considerada através de percentual sobre o capital total do fornecedor de investimentos em equipamentos que teriam de ser sucatados se eles fossem impedidos de levar adiante qualquer tipo de negócio futuro com a montadora. O percentual foi estimado pelos respondentes nas entrevistas.

Assume-se que a especificidade aumenta com a elevação do percentual do investimento de capital que não seria reutilizado. Para testar o ajuste geral das medidas com os dados, foi estabelecido um fator confirmatório de análise, no caso da pesquisa por Dyer e Chu. No caso da pesquisa no Brasil, para efeito de teste das hipóteses, foram utilizados os conceitos básicos como por Dyer e Chu, sem o fator confirmatório de análise, abaixo representado por (e), já que os primeiros dados provaram ser compatíveis e de medidas consistentes.

\section{Análise de Dados}

As três primeiras hipóteses foram testadas com dados coletados a partir dos fornecedores (i.e. a unidade de análise é o fornecedor) usando as seguintes regressões, de acordo com o estabelecido por Dyer e Chu. Ressalta-se aqui que, no caso da pesquisa no Brasil, não foi levada em conta o fator confirmatório de análise.

H1: Custo de Transação Ex Ante $=a+(b 1)$ CONFIABILIDADE + (b2) Especificidade de Ativos + e;

H2: $\quad$ Custo de Transação Ex Post $=a+(b 1)$ CONFIABILIDADE + (B2) Especificidade de Ativos + e;

H3: $\quad$ Compartilhamento de Informação do fornecedor $=a+(b 1)$ CONFIABILIDADE + (b2) Especificidade de Ativos + e. 
Revista Eletrônica de Ciência Administrativa (RECADM) - ISSN 1677-7387

Faculdade Cenecista de Campo Largo - Coordenação do Curso de Administração v. 3, n. 2, nov./2004 - http://revistas.facecla.com.br/index.php/recadm/

Para examinar a relação entre confiabilidade da montadora e seus custos de transação, foi testado o seguinte modelo usando dados coletados junto à montadora (unidade de análise é a montadora).

H4: CUSTO DE TRANSAÇÃO DA MONTADORA = a + (b1) CONFIABILIDADE DA MONTADORA.

A proxy utilizada para o custo de transação da montadora é a média de compras (em \$dólar por pessoa) no departamento de compras da montadora. As montadoras incorrem em custos reduzidos nas transações à medida que aumentam o valor em dólares por bens adquiridos através de cada comprador. Também a Confiabilidade da Montadora é o resultado efetivo da confiança que todos os fornecedores têm sobre uma montadora em particular.

\subsection{Resultados da análise de dados}

A estatística descritiva simples para a amostragem combinada e de cada país está na tabela 1 a seguir. A estatística descritiva indica que a confiabilidade do fornecedor é mais elevada no Japão que na Coréia ou nos Estados Unidos, os quais tiveram níveis similares de confiança do fornecedor, enquanto que o Brasil apresenta um nível de confiança do fornecedor menor que para todos os demais países comparados. Esses resultados do setor industrial sustenta o argumento anterior que a confiabilidade nas transações entre agentes japoneses é alta em relação a dos Estados Unidos e contradiz Fukuyama (1995) que diz que o Japão e Estados Unidos têm níveis similares de confiabilidade.

A estatística descritiva também mostra que os fornecedores japoneses têm custos de transação ex post menores, seguidos dos fornecedores americanos, enquanto medidas comparáveis para os fornecedores coreanos são muito altas. Isto ocorre claramente porque a forma de medir custos de transação é feita em termos de custo de transação por dólar vendido.

Tabela 1. Amostragem Combinada Total e por País

\begin{tabular}{|c|c|c|c|c|c|}
\hline \multirow[b]{2}{*}{ Variáveis } & Combin. & E.U.A. & Japão & Coréia & Brasil \\
\hline & $n=345$ & $\mathrm{n}=135$ & $n=101$ & $n=108$ & $n=11$ \\
\hline \multirow[t]{2}{*}{ 1. CONFIABILIDADE } & 13.90 & 13.63 & 16.37 & 13.21 & 12.40 \\
\hline & $(3.48)$ & $(2.64)$ & $(2.60)$ & $(3.48)$ & $(5.20)$ \\
\hline \multirow{2}{*}{ 2. CUSTOS DE TRANSAÇÃO Ex Ante } & 3.29 & .83 & .73 & 4.8 & 6.6 \\
\hline & $(7.60)$ & (1.62) & $(1.04)$ & (12.72) & (15.0) \\
\hline
\end{tabular}


Revista Eletrônica de Ciência Administrativa (RECADM) - ISSN 1677-7387

Faculdade Cenecista de Campo Largo - Coordenação do Curso de Administração v. 3, n. 2, nov./2004 - http://revistas.facecla.com.br/index.php/recadm/

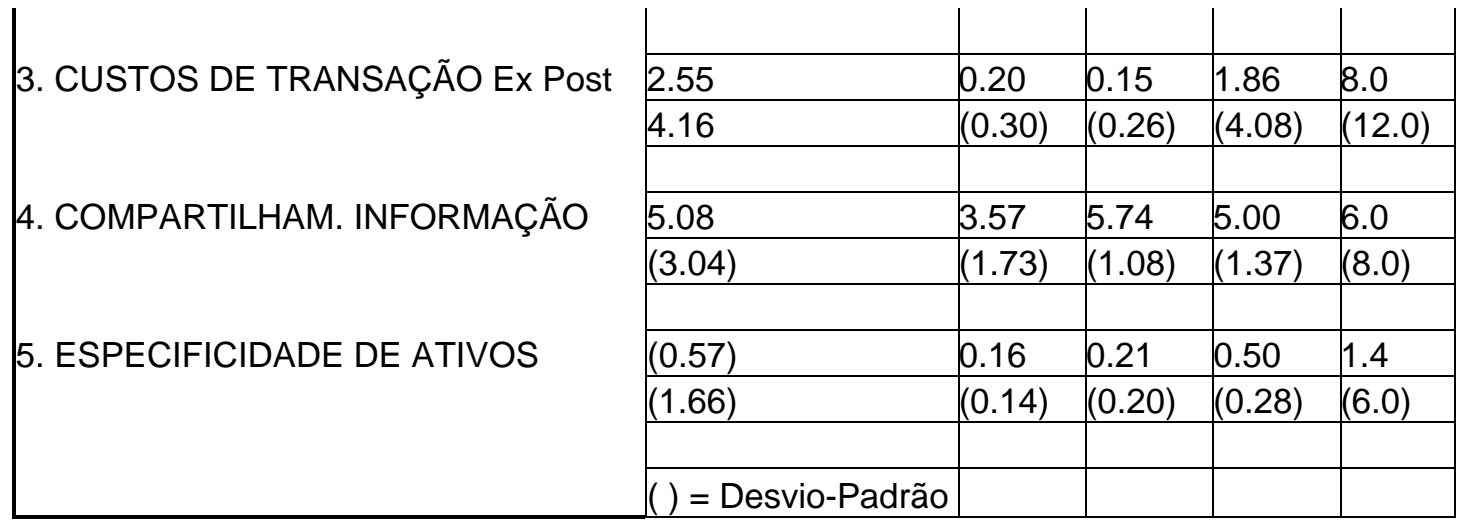

O Brasil ainda apresenta custos de transação ex post relativamente altos em comparação com aqueles outros países e isto decorre de vários fatores, inclusive pelo fato dos termos do contrato da montadora serem traduzidos do japonês para o português e, portanto, em alguns casos algumas traduções não são totalmente aplicáveis aos fornecedores instalados no Brasil, embora muito bem aceito pelos fornecedores de origem japonesa. Outro possível fator indicado pelos fornecedores para custos de transações ex post mais elevados que os outros países comparados é o fato incontestável pelos fornecedores a respeito de aumentos de preços ou de matéria-prima ou de mão-de-obra causados por mudanças institucionais do país, ou da região ou do local.

Tendo em vista que a média dos fornecedores coreanos é menor que um vigésimo em tamanho comparado àquele dos fornecedores japoneses $e$ americanos, o denominador é muito pequeno, resultando em alto custo de transação por dólar vendido. Aparentemente o custo de transação ex ante e ex post por dólar vendido pelos fornecedores coreanos é mais um resultado de (des)economia de escala que por ineficiências inerentes ao modo de conduzir seus negócios com as montadoras. Esses resultados na pesquisa no Brasil talvez não expressem o número total de fornecedores de peças instalados no país, entretanto, existe uma similaridade entre a situação brasileira e coreana neste aspecto.

As estatísticas descritivas também indicam que os fornecedores japoneses compartilham mais informações confidenciais que seus parceiros americanos e coreanos. Investimentos pelos fornecedores de peças em ativos específicos foram maiores na Coréia, seguidos pelo Japão e, então, Estados Unidos. Isto não é surpresa pois alguns estudos revelaram que $72 \%$ dos fornecedores de peças coreanos fornecem para apenas um cliente.

Através de uma análise de regressão para as primeiras três hipóteses, Dyer e Chu concluiram o seguinte:

Primeiramente, os dados indicam que a relação entre confiabilidade e custos de transação ex post é muito maior que a relação entre confiabilidade e custos de transação ex ante. Esta relação também foi encontrada no Brasil. Maior confiabilidade do fornecedor na montadora induz a custos de transação ex post 
Revista Eletrônica de Ciência Administrativa (RECADM) - ISSN 1677-7387

Faculdade Cenecista de Campo Largo - Coordenação do Curso de Administração v. 3, n. 2, nov./2004 - http://revistas.facecla.com.br/index.php/recadm/

menores no caso dos três países investigados por Dyer e Chu. Esse resultado com muita propriedade também é válido para o Brasil, na medida em que a montadora japonesa desde o início da relação se faz transparente ao fornecedor.

A relação entre confiabilidade e custos de transação ex ante não chega a ser significante, na medida em que, aparentemente, mesmo para relações de alta confiança, é necessário despender algum esforço para assegurar que cada agente econômico compreenda o seu papel, particularmente quando há envolvimento de especificidade de ativos elevada.

Portanto, de modo geral, a hipótese 1 não sustentada enquanto a hipótese 2 é confirmada nos casos do Japão e Estados Unidos e mais fraca no caso da Coreia. No caso do Brasil, pode-se dizer que a hipótese 1 é sustentada, dadas as condições gerais apresentadas, especialmente nos casos de fornecedores de origem não japonesa, os quais levam entre 12 e 24 meses para dar início a uma relação e, no caso da hipótese 2 , com muito mais propriedade ainda, pois o monitoramento se assevera na condição ex post justamente em virtude da vulnerabilidade dos fornecedores, principalmente em função de possíveis mudanças institucionais, as quais estão fora do controle tanto por parte da montadora quanto por parte do fornecedor.

Em segundo lugar, a análise sugere uma relação positiva entre confiabilidade do fornecedor e o compartilhamento de informações confidenciais ou valiosas pelo fornecedor. A hipótese 3 é plenamente sustentada no caso do Japão e Coreia, porém, com significância menor na amostragem dos Estados Unidos.

Finalmente, com relação a hipótese 4, examinou-se a correlação entre confiabilidade da montadora e custos de transação da montadora, medida através de valores em dólares dos bens adquiridos dos fornecedores por empregados da área de compras. Quando se focalizam custos de reaprovisionamento relativo para cada montadora, juntamente com os resultados da confiabilidade da montadora, revela-se uma correlação significativa e forte. Os resultados indicam que uma firma $A 1$, que tinha baixa confiabilidade do fornecedor, incorreu em custos de transação que eram mais de duas vezes maiores que de outras firmas americanas; firmas A2 e A3 tiveram quase seis vezes mais que a firma $\mathrm{J} 1$ no Japão. Portanto, os dados oferecem suporte a hipótese 4.

Para confirmar a ligação entre confiabilidade, custos de transação menores e performance financeira, averiguou-se que a correlação entre a confiabilidade de cada montadora, seus custos de transação e lucratividade média (ROA ou lucros antes dos impostos divididos pelos ativos) entre os anos 1985 e 1995. Os resultados indicam uma forte correlação entre a confiabilidade da montadora e custos de transação (medido como reaprovisionamento de produtivos). Os resultados também mostram uma forte correlação entre a confiabilidade da montadora e a performance dos lucros.

Embora haja um bom número de fatores que indubitavelmente influenciam diferenças entre montadoras, esses resultados sugerem que a confiabilidade é 
Revista Eletrônica de Ciência Administrativa (RECADM) - ISSN 1677-7387

Faculdade Cenecista de Campo Largo - Coordenação do Curso de Administração v. 3, n. 2, nov./2004 - http://revistas.facecla.com.br/index.php/recadm/

um fator de contribuição porque ela reduz os custos de transação das montadoras, portanto, melhora a lucratividade da montadora.

No Brasil, devido às dificuldades de coleta de dados junto a alguns fornecedores, o estudo ficou prejudicado de modo que não pôde ficar evidenciada a confirmação da hipótese 4 de modo total. De modo parcial, portanto, não necessariamente evidenciado, os dados colhidos junto às fontes que tiveram abertura neste sentido, indicam que a confiabilidade pode reduzir custos de transação das montadoras, resultando em aumento na sua lucratividade.

\section{Considerações finais}

Os resultados encontrados indicam que a confiabilidade reduz custos de transação e é correlata com o aumento do compartilhamento de informações nas relações entre fornecedores e montadoras. Além disso, o valor econômico criado pelos agentes econômicos, em termos de menores custos de transação, aparenta ser substancial na indústria automotiva. Entretanto, é importante alertar que a validade das ligações causais implicadas no modelo de Dyer e Chu é limitada pela natureza do desenho da pesquisa. Também é importante alertar que os resultados devem ser considerados somente para a indústria automobilística ou outras indústrias com características similares, isto é, indústrias de produtos complexos como aeronáutica, maquinário pesado, robótica, supercomputadores, etc. Por indústria de produtos complexos entende-se aquela classificada como de alto grau de interdependência mútua ou recíproca com fabricantes de componentes intermediários ou de montadoras finais.

Acredita-se que a confiabilidade nas relações entre fornecedores e montadoras pode ser uma fonte importante de vantagem competitiva nos arranjos industriais, nos quais: (1) custos de transação podem ser elevados devido a condições que criam dificuldades transacionais, por exemplo incerteza ambiental e alta especificidade de ativos interfirmas e (2) haja um elevado valor associado ao compartilhamento de informação, onde a informação é um recurso valoroso devido a complexidade de produto e incerteza da indústria.

A confiabilidade nas trocas econômicas tem sido vista por alguns analistas como ativo econômico de valor em razão dos custos de transação inferiores, os quais permitem maior flexibilidade para responder às condições de mercado em constantes mudanças e induzem a um maior compartilhamento de informações, que provoca melhorias na coordenação e estrutura de governança, juntando assim esforços para minimizar as ineficiências. 
Futuras pesquisas a exemplo destas aqui apresentadas e outras que tratam de arranjos múltiplos de indústrias podem eventualmente dar luz tanto à validade das ligações causais aqui sugeridas quanto a ampliar os resultados a outros tipos de indústrias.

Referências

ANFAVEA - ASSOCIAÇÃO NACIONAL DOS FABRICANTES DE VEÍCULOS AUTOMOTORES - Anuário Estatístico da Indústria Automobilística Brasileira. 2003. São Paulo: A Associação 1996-2002. 152 p.

DORE, Ronald. Goodwill and the spirit of market capitalism. British Journal of Sociology. XXXIV (4), 1983, p. 459-482

DRUCKER, Peter. The Concept of the Corporation. New York: John Day, 1946, 297 p.

DYER Jeffrey; CHU, Wujin. The role of trustworthiness inreducing transaction costs and improving performance. Organization Science; Jan/Fev. 2003; 14, 1; ABI/INFORM Global, p. 57

FUKYAMA, Francis. Trust: The Social Virtues and the Creation of Prosperity. The Free Press, New York, 1995

HILL, Charles W. L.. National institutional structures, transaction cost economizing, and competitive advantage: The case of Japan. Organization Science, 6 (2), 1995, p. 119-131

KLEIN et al. Vertical Integration, appropriable rents and the competitive contracting process. Journal of Law and Economics. 21, 1978, p. 297-326

MAYER et al. An integrative model of organizational trust. Academic Management Review. 20 (3), 1995, p. 709-734

QUADROS, Ruy et al. Globalização e Reestruturação da Cadeia Produtiva da Indústria Automobilística: qual é o papel do Mercosul? Relatório Final de Pesquisa para o IPEA. Mimeo. Campinas: GEMPI/DPCT/IG/Unicamp, 2000

QUADROS, Ruy. Global Quality Standards, Chain Governance and the Technological Upgrading of Brazilian Auto-Components Producers. Brighton: Institute of Development Studies, 31 p. Working Paper n. 156, Maio de 2002.

SAKO, Mari. The role of "trust" in Japanese buyer-supplier relationships. Ricerche Economiche XLV (2-3), 1991, p. 449-474 
Revista Eletrônica de Ciência Administrativa (RECADM) - ISSN 1677-7387

Faculdade Cenecista de Campo Largo - Coordenação do Curso de Administração v. 3, n. 2, nov./2004 - http://revistas.facecla.com.br/index.php/recadm/

SHANE, s. The effect of national culture on the choice between licensing and direct foreign investments. Strategic Management Journal 15, 1994, p. 627642

WILLIAMSON, Oliver. Comparative economic organization: The analysis of discrete structural alternatives, Administrative Sciences. Quart. 36, 1991, p. 269-296.

WOMACK et al. A Máquina que Mudou o Mundo. Rio de Janeiro: Campus Editora, 1992, 347 p.

YIN, Robert K. Designing Case Studies. In:_Case Studies Research: Design and Methods. London: Sage Publications, $2^{\text {nd }}$ edition, 1994 , cap. 2 , p. 18-53 (Edição em português).

ZAHEER et al. Does trust matter? Exploring the efrects of interorganizational and interpersonal trust on performance. Organizational Science. 9 (2), 1998, p. 141-159.

Autores:

Elio Ferrato

Eduardo Eugênio Spers

Antonio Carlos Giuliani

Faculdade Cenecista Presidente Kennedy

Coordenação do Curso de Administração

Prof. MSc. Alexandre Shigunov Neto

Campo Largo - PR

Junho de 2004 
Revista Eletrônica de Ciência Administrativa (RECADM) - ISSN 1677-7387 Faculdade Cenecista de Campo Largo - Coordenação do Curso de Administração v. 3, n. 2, nov./2004 - http://revistas.facecla.com.br/index.php/recadm/ 
Revista Eletrônica de Ciência Administrativa (RECADM) - ISSN 1677-7387 Faculdade Cenecista de Campo Largo - Coordenação do Curso de Administração v. 3, n. 2, nov./2004 - http://revistas.facecla.com.br/index.php/recadm/ 